Dossier: El Quehacer de las Humanidades: Acción Social, Investigación y Metodologías e Innovación Tecnológica en la Docencia

\title{
El propósito de la formación humanista en la Universidad de Costa Rica del siglo XXI
}

\author{
Jorge Alberto Monge Ortiz \\ Universidad de Costa Rica, Costa Rica \\ jorge.monge@yahoo.com \\ https://orcid.org/0000-0002-0888-4184
}

Recibido: 3 de octubre de 2019

Aceptado: 15 de enero de 2020

Resumen: El presente artículo plantea la necesidad de las humanidades en la formación profesional del estudiante que entra en la Universidad de Costa Rica con el fin de rescatar una visión integral que coadyuve en la inserción ética del egresado de la educación superior.

Palabras clave: humanidades; formación humanística; formación profesional; educación superior; Universidad de Costa Rica.

\section{The purpose of humanist formation at the University of Costa Rica of the 21st century}

\section{(c) (i) (2) (2)}

La Revista Estudios es editada por la Universidad de Costa Rica y se distribuye bajo una Licencia Creative Commons Atribución-NoComercial-Compartirlgual 3.0 Costa Rica. Para más información envíe un mensaje a 


\section{Especial: Profesores de Estudios Generales investigan}

Abstract: This article raises the need of the humanities in the professional training of the student who enters the University of Costa Rica in order to rescue a comprehensive vision that assists in the ethical insertion of the graduate of higher education.

Keywords: humanities; humanistic training; vocational training; higher education; Costa Rica University.

\section{Presentación}

La Universidad de Costa Rica se distingue por los tres pilares fundamentales, que son tres áreas del conocimiento que le permiten ser la más destacada del país: la docencia, la acción social y la investigación. En ese sentido, no es casual que se proyecte como un centro de formación profesional integral, que inicia con los cursos de humanidades, los cuales hacen que se coloque a la vanguardia de la enseñanza superior.

La Escuela de Estudios Generales es la que le da la bienvenida a los futuros profesionales con una variedad de cursos que incorporan al estudiantado a una formación general y humanista los cuales permiten su inserción a un modelo epistemológico cuyo objetivo es integrar a la persona a la sociedad. Esto es, propiciar la reflexión sobre la sociedad, no sólo de manera teórica sino también práctica, con proyección de su integridad en lo que será su futura profesión, que lo ocupará con mucha probabilidad en el devenir histórico de sí mismo. Es de esta forma que la preocupación inicial de la Escuela de Estudios Generales es la formación ética, profesional e integral del joven que inicia el camino de la búsqueda de su tarea como ciudadano del mundo. Surge entonces de esta inquietud colectiva la siguiente pregunta: ¿por qué y para qué se da la formación humanista en la Escuela de Estudios Generales en la Universidad de Costa Rica?

\section{(c) (i) (2) (2)}

La Revista Estudios es editada por la Universidad de Costa Rica y se distribuye bajo una Licencia Creative Commons Atribución-NoComercial-CompartirIgual 3.0 Costa Rica. Para más información envíe un mensaje a 
ISSN 1659-3316

Especial: Profesores de Estudios Generales investigan

\section{El propósito de las humanidades}

El propósito $u$ origen de las humanidades es integrar a la persona a la sociedad, no solamente como técnico de saberes sino a sí mismo como parte de ese colectivo que, dentro de lo complejo, necesita de individuos que formen parte de la lucha por mejorar el conocimiento integrado de esos saberes en beneficio de los demás.

Hace mucho tiempo plantee la siguiente inquietud a estudiantes de ingeniería: ¿para qué es un puente? Dentro de las respuestas, que creí obvias, estaban la mayor variedad de disquisiciones sobre la física y la matemática que salieron a flote con el anhelo de explicarme de manera sencilla los devenires matemáticos de la construcción de un puente. Ello a la luz del tiempo que habían empleado en los cursos iniciales de cálculo. Sin embargo, no logré que me respondieran hasta años después la respuesta esperada: un puente es para pasar. Y precisamente esa respuesta la obtuve en la Universidad de Costa Rica.

Con lo anterior he constatado que las verdades de sentido común se pierden muchas veces en el proceso de adquisición del conocimiento técnico, precisamente porque la técnica hace o deviene en una hiper especialización del joven de manera tal que se le olvida cuál es el fin no sólo de su formación, sino también del objetivo para el cual se encuentra en la Universidad.

Volví otra vez a hacerme la pregunta sobre la función de las humanidades en la formación profesional a partir de la situación que, en un centro médico, vivió un amigo. Él tiene unos treinta años y hace poco sufrió un accidente en el trabajo en el cual prácticamente se cercenó una mano. En el hospital lo hicieron esperar durante muchos días durante los cuales había soportado el dolor hasta que accidentalmente su esposa se dio cuenta del motivo por el cual no lo habían operado. De casualidad escuchó al médico que lo tenía a cargo preguntar un poco

\section{(c) (i) (2)}

La Revista Estudios es editada por la Universidad de Costa Rica y se distribuye bajo una Licencia Creative Commons Atribución-NoComercial-CompartirIgual 3.0 Costa Rica. Para más información envíe un mensaje a 
Especial: Profesores de Estudios Generales investigan

molesto el motivo por el cual no le habían amputado la mano, ello por la pérdida de tiempo que significaba tener el paciente tantos días allí. La enfermera, con discreción, le preguntó al galeno si procedía la amputación de la mano de mi amigo puesto que, a su vez, era amigo de la enfermera. El joven médico dejó su enojo, lo pensó entonces y de manera inmediata ordenó que no se le amputara la mano sino la intervención de la misma para salvarla y su pronta recuperación.

La pregunta en ambos casos viene a ser prácticamente la misma: ¿dónde queda la formación humanística en los jóvenes que pierden de vista que la función de un puente es para pasar o que deciden sobre la amputación de una persona en un par de segundos a partir de la premura del tiempo que se supone siempre tiene alguien como un médico?

Asimismo podemos enunciar: ¿se forman al estudiantado con el fin de convertirse en trabajadores técnicos cuyo objetivo es la obtención de mecanismos de poder para conseguir dinero y olvidarse de que se trabaja para los demás?

Es a partir de aquí que se plantea esta reflexión: ¿se puede perder lo humano en el profesional graduado de la Universidad? ¿En qué momento se deben dar la formación en humanidades con el fin de que el joven no pierda de vista su integración en la sociedad?

Las inquietudes surgen de la reacción que tuvo el médico cuando, como profesional, vio la salida más fácil: la amputación de la mano. Realmente y en el sentido práctico, el joven galeno no volvería a ver al paciente y simplemente resumiría el proceso en una deshumanizada amputación que le hubiera cambiado la vida a mi amigo. El caso de la reconstrucción de la mano, que fue lo que dichosamente sucedió, es el camino difícil, que requiere tiempo y esfuerzo. No hay duda de que todos estos factores están enlazados con una formación profesional. La formación en humanidades no es efímera, muestra la tarea de la profesión por encima de lo egoísta y se evidencia en el contacto con los demás, llámese peatón o paciente.

\section{(a) $\mathbb{Q} \Theta($}

La Revista Estudios es editada por la Universidad de Costa Rica y se distribuye bajo una Licencia Creative Commons Atribución-NoComercial-CompartirIgual 3.0 Costa Rica. Para más información envíe un mensaje a 
ISSN 1659-3316

\section{La formación en humanidades}

\section{Especial: Profesores de Estudios Generales investigan}

La formación en humanidades es la que establece la diferencia entre un técnico y un profesional, sea en la especialidad que sea. La tekné, en el sentido amplio, incluye la transformación, más propiamente la transformación del conocimiento en herramienta para cooperar en el desarrollo social. Así, esta amplía el criterio para no limitarse al ejercicio del conocimiento por el conocimiento. Al respecto se puede poner por ejemplo la opinión del cardiólogo Guillermo Carvajal Alvarado en su libro: Los Estudios Generales en la Universidad de Costa Rica (2005) cuando examina la diferencia de miras entre los especialistas médicos:

"Saber la clínica tradicional, dominar las técnicas usuales, estar enterado de las doctrinas corrientes, eso basta para hacer un cardiólogo práctico, pero no un especialista en Cardiología. Los primeros son clínicos en el noble sentido de la palabra, pero de actividad circunscrita, clínicos de vuelo corto, muy útiles a la comunidad social, pero lo son menos de la comunidad científica. Los verdaderos especialistas, en cambio, son los que pueden hacer avanzar los conocimientos de su ramo". (Carvajal, 2005, p. 105).

La barbarie especialista define la crueldad a ultranza que lleva a los errores en la profesión. En las personas que tienen cierto nivel de poder, los hace incurrir en comportamientos antiéticos, como el que lleva a decidir amputarle la mano a una persona por la pereza de trabajar. Así, la presencia de la barbarie especialista en la profesión tiene su auge en la falta de visión de integral del entorno.

Esta separación se logra compensar con la intervención en la formación del estudiantado universitario, lo cual se busca con la existencia de los cursos de humanidades. Según el Estatuto Orgánico la Universidad de Costa Rica la institución se dedica a la "enseñanza, la investigación, la acción social, el estudio, la meditación, la creación artística y la difusión del conocimiento" (Artículo 1). Por ello, buena parte de este Estatuto Orgánico se procura con la formación del

La Revista Estudios es editada por la Universidad de Costa Rica y se distribuye bajo una Licencia Creative Commons Atribución-NoComercial-CompartirIgual 3.0 Costa Rica. Para más información envíe un mensaje a 


\section{Especial: Profesores de Estudios Generales investigan}

estudiante en la Escuela de Estudios Generales, que es precisamente la que brinda los cursos de humanidades.

En relación con las humanidades, los cursos de Comunicación y Lenguaje, Historia de la Cultura y la Filosofía y Pensamiento, se presentan como un abanico de posibilidades para la juventud que llega al Alma Mater; asimismo, la Guía Académica plantea la antesala de un proyecto de tesina que fungirá como antelación de la añorada tesis de grado, a la cual se llegará cuando finalice el programa de estudios de la carrera. En la misma dirección, las otras opciones que brinda la Escuela de Estudios Generales brindan las herramientas necesarias para ampliar el tema que, se espera, ocupará a los jóvenes el resto de sus días como profesionales y ciudadanos: pensar de forma crítica con el fin de poner al servicio de los otros su conocimiento.

Se trata de una labor ontológica urgente, la formación de valores, no del tener sino del ser. Las y los jóvenes precisan de ser hoy día, pues el tener ya se encuentra mitificado en la sociedad actual de consumo. Por ello, la inserción en esta sociedad se deberá hacer con prudencia en la medida que ayudará el oficio de pensar. La filosofía tiene como labor básica esta tarea. Se precisa dar a entender lo que saben y piensan, la comunicación será el saber que coadyuvará en este esfuerzo. Asimismo se necesita el recuerdo de lo que se hizo antes, en esta labor contribuirá el estudio de las coyunturas históricas. La investigación canalizará la curiosidad y el planteamiento del saber crítico en la medida que será el primer paso en un entorno muchas veces de personas que ya no preguntan.

De esta manera, se presenta la importancia de las humanidades en el siglo XXI, ya que se trata de una labor ingente, no sólo para la inserción del joven adulto en el mundo que le toca vivir, sino también en la medida que puede hacer mejores personas en el contexto dentro y fuera de la Universidad. En este caso se justifica que la Universidad de Costa Rica, y específicamente la Escuela de

\section{(c) (i) (9) (2)}

La Revista Estudios es editada por la Universidad de Costa Rica y se distribuye bajo una Licencia Creative Commons Atribución-NoComercial-CompartirIgual 3.0 Costa Rica. Para más información envíe un mensaje a 


\section{Especial: Profesores de Estudios Generales investigan}

Estudios Generales, procuren esta formación; tal y como se sostiene en el libro de Gerardo Contreras Reflexionar la Universidad (2009):

"El hombre y la mujer no son, se hacen. El ser humano existe. Su esencia se constituye con y a través de la cultura. Este proceso de constitución lo llamamos humanizarse. La universidad y particularmente los Estudios Generales adquieren su justificación y necesidad cuando posibilitan este proceso. La existencia de las Humanidades en la Universidad de Costa Rica, hacen de ella una verdadera "Alma Máter". Los Estudios Generales no son otra cosa, sino que la gran puerta que tienen los ciudadanos costarricenses para entrar en el Universo de la Cultura y para hacerlo crecer según sus potencialidades espirituales e intelectuales". (Contreras, 2009, p. 29, la negrita es nuestra).

Es mediante el conocimiento que el ser humano encuentra no sólo el dominio de su entorno sino la puerta, tal y como afirma el autor anterior, para abrir las posibilidades del ser. Esa puerta constituye la apertura de las personas hacia la libertad.

A través de las humanidades, en la Universidad de Costa Rica se cultiva la labor más encomiable que se encuentra en el Estatuto Orgánico: el pensamiento crítico, y además, la cualidad de los costarricenses por antonomasia: la de ser libres, y la de las personas por excelencia: la de ser. Esta experiencia que parece banal, no lo es. Se trata del hilo contrario de lo que se cultiva a mansalva en las empresas que se dedican a la educación como negocio; y es por tanto un distintivo útil que requiere seguir siendo valorado.

\section{Las humanidades en el siglo XXI}

Existe hoy día en el nivel del mercantilismo cognitivo y entre las personas jóvenes, un desmerecimiento de las Humanidades y de las Ciencias Sociales argumentando que no contienen cursos ni carreras "productivas" según algunas perspectivas de índole neoliberal. Esto lleva a una carencia social que se origina en la avaricia mal entendida, la cual inicia precisamente en el proceso de la

\section{(c) (i) (2)}

La Revista Estudios es editada por la Universidad de Costa Rica y se distribuye bajo una Licencia Creative Commons Atribución-NoComercial-CompartirIgual 3.0 Costa Rica. Para más información envíe un mensaje a 
Especial: Profesores de Estudios Generales investigan

educación tal y como sostiene Martha Nussbaum en su libro: Sin fines de lucro. Por qué la democracia necesita de las humanidades (2010):

"Se están produciendo cambios drásticos en aquello que las sociedades democráticas enseñan a sus jóvenes, pero se trata de cambios que aún no se sometieron a un análisis profundo. Sedientos de dinero, los estados nacionales y sus sistemas de educación están descartando sin advertirlo la democracia. Si esta tendencia se prolonga, las naciones de todo el mundo en breve producirán generaciones enteras de máquinas utilitarias, en lugar de ciudadanos cabales con la capacidad de pensar por sí mismos, poseer una mirada crítica sobre las tradiciones y comprender la importancia de los logros y los sufrimientos ajenos. El futuro de la democracia a escala mundial pende de un hilo". (Nussbaum, 2010, p. 20).

Nos encontramos entonces, y según lo anterior, ante una pérdida de valores tan importantes como el humanismo en los profesionales y la capacidad de una mirada crítica del entorno. Desde esta perspectiva la información avanza pero no la comunicación efectiva que pone en común el bien de todos. La democracia ya no es representativa sino un aparato ideológico que funciona como un cascarón para llenar los salones de clase, de representaciones vacuas relacionadas con la efemérides del momento. La plutocracia sustuye a la democracia.

Es evidente que el logro como sinónimo de éxito se da mediante la mercantilización de la educación, lo cual vendría a hundir a los ciudadanos en la valoración de lo económico por encima de las humanidades. Ya no tendría sentido la práctica de la profesión sino el dinero que esta pueda proveer. Sería la gloria de la publicidad a favor de las universidades como negocio y no como el origen del desarrollo de los pueblos.

En estas dos primeras décadas del siglo XXI, se dan entre los estudiantes universitarios costarricenses dos coordenadas que van en contra de las humanidades y en detrimento de la Universidad Pública:

a. En primer lugar se plantean las humanidades como un gasto de tiempo y no como una inversión de la manera más comercial que se 


\section{Especial: Profesores de Estudios Generales investigan}

pueda. En este sentido no se puede hacer nada por las humanidades pues se circunscriben en el campo de lo inútil desde una mirada mercantil.

La inversión de tiempo que requiere hacer en el curso de humanidades implica en esta perspectiva una pérdida de tiempo. Ante ello, de manera más asertiva y en relación con el factor tiempo habría que preguntarse sobre cuál es el tiempo que lleva educarse profesionalmente: ¿cuál es el tiempo que le lleva a un ingeniero hacerse ingeniero? ¿Cuál es el tiempo que le lleva a un sociólogo dominar los intríngulis de los movimientos que llevan a la pobreza a una sociedad?

La idea semántica que estructura esta ideología consumista oculta, sería precisamente que la educación es rápida y que no hay tiempo que perder en el objetivo mercantil de la educación: el graduarse. Existe una espera en la cual el interés por el título supera a la educación misma pues no interesa en sí sino en la medida que se puede obtener un "permiso" social que lleve al estudiante a mejorar sus ingresos y no así su formación.

b. En segundo lugar tenemos la inversión de dinero. La dicotomía menos tiempo y más dinero. Los medios de comunicación como generadores de información y columnas ideológicas de una sociedad de consumo incentivan en la juventud el valor del éxito entendido como obtener el puesto de la gerencia o la oficina de cristal en poco tiempo. Este proceso se vuelve contraproducente con el disfrute que puede tener el estudiar algunas de las carreras que la sociedad de consumo considera como improductivas y que sólo pueden encontrar respaldo en el Estado.

Se tiene entonces la filosofía como un lujo, el leer como una acción innecesaria y la historia como un proceso inútil de la memoria que bien, según alguna mentalidad pueril del siglo XXI, puede estar en un celular.

Para algunos jóvenes costarricenses del siglo XXI, y en algunas sociedades contemporáneas, las humanidades se vuelven un obstáculo que no 
Especial: Profesores de Estudios Generales investigan

tiene sentido más allá del aula, puesto que no tiene, según su parecer, beneficio económico inmediato. Es ahí donde esta reflexión es necesaria, pues en un mundo como el contemporáneo no se pueden establecer juicios a la ligera.

\section{El aporte de las humanidades}

Las humanidades centran sus análisis en la persona, en su comportamiento en sociedad. De ahí viene entonces la Historia para recuperar la memoria de los hechos y no volverlos a repetir o repetirlo si han sido beneficiosos de la humanidad. De ahí también la Filosofía que deviene en ética, en la medida que cuestiona el quehacer humano en relación con el medio, entre otros. Y la Literatura y la Comunicación que igualmente recuperan la memoria y tratan de mejorar el intercambio de todos los días: lingüistico, simbólico y comprensivo. Ahora bien, no se entenderían las humanidades sin una visión integral que contenga también investigación, que se proyecte a la comunidad y que parta de la excelencia docente, más aún en una Universidad que mira en esas tres direcciones según se indicó al inicio.

El pensamiento humanístico requiere de la presencia de las Artes y las Ciencias que nos llevan a apreciar a Vivaldi, a Chejov, a Chopin, a Einstein o a Salvador Dalí. Es decir, que invita al desarrollo del ser, no solamente de la cualidad humana, de la productividad, que es desde donde la persona tiene la posibilidad de envilecerse a sí mismo como una máquina, sino a la esencia del ser humano como tal.

¿Cuál sería la función de leer una novela como El amor en los tiempos del cólera en los tiempos de la neurociencia? ¿O cuál es la función de leer La Odisea en los años del waze? La respuesta ingenua y apresurada sería: ninguna. La respuesta desde las humanidades sería el pensamiento crítico de las relaciones sociales, de la mitología, de la aventura, incluso de la superación personal en los 
Especial: Profesores de Estudios Generales investigan

personajes de Florentino Ariza, Fermina Daza y Odiseo como búsquedas que se plantean las personas para explicarse a sí mismos e imaginar otros mundos posibles.

La Literatura, la Comunicación, la Filosofía, el Pensamiengo y la Historia proponen los saberes necesarios para no caer precisamente en el ser humano técnico en el sentido utilitario mercantil de la palabra. Habría entonces en esta parte que citar a Nuccio Ordine en su libro La utilidad de lo inútil (2013) sobre los saberes que, apresuradamente se comprenden como inútiles:

"La utilidad de los saberes inútiles se contrapone radicalmente a la utilidad dominante que, en nombre de un exclusivo interés económico, mata de forma progresiva la memoria del pasado, las disciplinas humanísticas, las lenguas clásicas, la enseñanza, la libre investigación, la fantasía, el arte, el pensamiento crítico y el horizonte civil que debería inspirar toda actividad humana." (Ordine, 2013, p. 6 ).

Según este autor, hay que evitar caer en el universo del utilitarismo que hoy día le da forma a todo un mundo de prejuicios en torno a lo que es útil y a lo que no:

"En el universo del utilitarismo, en efecto, un martillo vale más que una sinfonía, un cuchillo vale más que una poesía, un llave inglesa vale más que un cuadro: porque es más fácil hacerse cargo de la eficacia de un utensilio mientras que resulta cada vez más difícil entender para qué puede servir la música, la literatura o el arte." (Ordine, 2013, p. 6).

En contraposición con la apreciación inútil de la educación humanística habría que anteponer la definición de Werner Jager de la Educación en su obra clásica Paideia: los ideales de la cultura griega (2010): "La educación no es posible sin que se ofrezca al espíritu una imagen del hombre tal y como debe ser. En ella la utilidad es indiferente o, por lo menos, no es esencial." (Jager, 2010, p. 19).

El universo del deber ser de la formación humanística inicia con el pensamiento crítico presente en las humanidades. No tiene sentido la educación

La Revista Estudios es editada por la Universidad de Costa Rica y se distribuye bajo una Licencia Creative Commons Atribución-NoComercial-CompartirIgual 3.0 Costa Rica. Para más información envíe un mensaje a 
Especial: Profesores de Estudios Generales investigan

parcializada, tal y como se hace en la educación secundaria costarricense, puesto que esta segmentación sume al estudiante en la barbarie especializada, en la medida que ya no interesa el entorno total e integral, por ejemplo, sino el entorno propio. Se estudia Español divorciado de los Estudios Sociales, Ciencias divorciado de Computación, es decir, no existe el eje multidisciplinario que descubre el estudiante en la Universidad de Costa Rica.

$\mathrm{Si}$ el conocimiento se encuentra segmentado igualmente se fisura también la solidaridad social. Todo se encuentra segmentado con un sentido arraigado de la individualidad. La Universidad posibilita la vuelta a esa integración del conocimiento para que el estudiantado se encuentre, específicamente en las humanidades, en el inicio de la carrera profesional y así pueda ampliar sus horizontes.

El avance del conocimiento se debe precisamente a lo que Manuel Castells llama La sociedad red (2006), la cual define hoy la cultura y el progreso de las personas y los países, quienes se encuentran en constante cambio debido al avance vertiginoso de la tecnología, modificando la estructura social. Pero ello no implica facilismo o ligereza.

Si se quiere cumplir con el cometido de la Universidad como una red de origen de conocimiento, que no puede ni debe constituirse en una cadena de empresas, que se caracterice por la dualidad costo-beneficio; se deben implementar las humanidades. No se debe mercantilizar la interdisciplinariedad de los saberes.

En la Universidad se trabaja con el conocimiento, el cual no cae en la reglas del mercado puesto que enriquece tanto el discente como al docente y es en este sentido, que se puede volver a citar a Ordine, porque "El conocimiento es una riqueza que se puede transmitir sin empobrecerse." (Ordine, 2013, p. 58).

El mismo Ordine observa los beneficios del humanismo en contraste con los intereses que hoy permean al individuo: "la posesión y el beneficio matan, 
Especial: Profesores de Estudios Generales investigan

mientras que la búsqueda, desligada de cualquier utilitarismo puede hacer a la humanidad más libre, más tolerante y más humana."(Ordine, 2013, p. 70).

\section{Conclusiones}

Se debe volver a la Educación como el eje originario de la democracia, de la epistemología crítica. Es decir, la educación integral que sostiene socialmente a un país, cuya riqueza va más allá de su sistema en cuanto requiere ser humanístico, tal y como lo plantea el Estatuto Orgánico de la Universidad de Costa Rica.

No es casual entonces que la Universidad de Costa Rica se diferencie implementando los Estudios Generales y la formación que estos brindan en humanidades. En ellas, el eje de sentido es volver con el estudiante a pensar de forma crítica e integral el rumbo de los jóvenes mismos en su contexto. De volver a pensar la democracia una y otra vez, por medio del Arte, de la Historia, de la Filosofía, la Comunicación y la Ciencia. De volver a pensar que no sólo es importante ser médico o ingeniero o cardiólogo, también es importante el paciente, el paso de las personas o el corazón.

Por ello, se debe rescatar que las humanidades brindan las siguientes ventajas para el futuro profesional:

a. El entendimiento de la sociedad de manera integral, no solamente como una maquinaria de consumo que se transforma poco a poco en un artilugio de desconocimiento e indiferencia hacia los demás.

b. El desarrollo de una visión crítica contextual que coadyuve con la visión y opinión que tiene el ser humano de sí mismo y de su entorno para no caer en la propia destrucción.

\section{(C) $(\Theta \odot$}

La Revista Estudios es editada por la Universidad de Costa Rica y se distribuye bajo una Licencia Creative Commons Atribución-NoComercial-CompartirIgual 3.0 Costa Rica. Para más información envíe un mensaje a 
Especial: Profesores de Estudios Generales investigan

c. La investigación como una herramienta con la que aprende el estudiante a sustentar el conocimiento como instrumento de progreso individual y social.

d. La necesidad de evitar la especialización a ultranza. Es decir, el no olvidar que el conocimiento adquiere sentido solamente si es social.

e. La insistencia que el progreso no es individual, es en equipo.

f. El establecimiento de metas en común.

g. La comprensión del contexto histórico con el fin del entender el pasado en función del futuro.

h. Entender la construcción de la identidad a través de la comunicación y los problemas estructurales que se plantean en la aldea global.

i. Poder darle solución a los problemas éticos que generan los avances de la tecnología y las nuevas redes sociales del siglo XXI.

j. Aprender a decir y a escuchar y poder de esta manera respetar a los otros así como a nuestro ambiente para poder convivir con todos en paz.

No hay duda, la Escuela de Estudios Genrales distingue a la Universidad de Costa Rica y es necesaria, aún más en los tiempos que corren. En la medida que se fortalezca este país tendrá profesionales con una visión integral que bien puedan apreciar la belleza de un puente o la recuperación de la mano que alguien se accidentó, o la estructura semántica de un poema; y van a poder establecer puentes que unan los caminos en la búsqueda tanto del conocimiento como de los aspectos que brindan sentido a la adquisición del conocimiento para solidarizarse con los demás.

\section{(c) (i) (2)}

La Revista Estudios es editada por la Universidad de Costa Rica y se distribuye bajo una Licencia Creative Commons Atribución-NoComercial-CompartirIgual 3.0 Costa Rica. Para más información envíe un mensaje a 


\section{Bibliografía}

\section{Especial: Profesores de Estudios Generales investigan}

Carvajal, G. (2005). Los Estudios Generales en la Universidad de Costa Rica. San José: Costa Rica.

Castells, M. (ed.). (2006). La sociedad red: una visión global. Madrid: Alianza Editorial.

Consejo Universitario. Estatuto Orgánico de la Universidad de Costa Rica.

Contreras, G. (2009). Reflexionar la universidad. San José: Ediciones Estudios Contemporáneos: Cátedra Bicentenario Latinoamericano.

Jager, W. Paideia. (2010). Los ideales de la cultura griega. México D. F.: Editorial del Fondo de Cultura Económica.

Nussbaum, M. (2010). Sin fines de lucro. Por qué la democracia necesita de las humanidades. Buenos Aires: Katz Editores.

Ordine, N. (2013). La utilidad de lo inútil. Manifiesto. Barcelona: Editorial Acantilado.

\section{(c) (i) (2)}

La Revista Estudios es editada por la Universidad de Costa Rica y se distribuye bajo una Licencia Creative Commons Atribución-NoComercial-CompartirIgual 3.0 Costa Rica. Para más información envíe un mensaje a 